\title{
Recent progress on the water-energy-food nexus using bibliometric analysis
}

\author{
Dan Chen, Peng Zhang, Zhaohui Luo*, Di Zhang, Bo Bi and Xinchun Cao
}

A systematic overview of the water-energy-food nexus studies is presented using bibliometric analysis. We have used the Web of Science Core Collection data from 2010 to 2017 for the same. The main subject categories include environmental science and water resources. Water and Environmental Science \& Policy are two typical journals. USA, England and Germany are productive countries, while the main institutions are Oxford University, International Water Management Institute, and International Food Policy Research Institute. The frequently cited papers and keywords revealed the research hotspots and trends, with the major concerns of the concept and mechanism, research dimensions and nexus methodologies.

Keywords: Bibliometric analysis, recent progress, systematic overview, water-energy-food nexus.

WATER, food and energy security is of crucial importance for the sustainable development of mankind. Driven by climate change, economic growth, urbanization, global population increase and changing consumption style, global demand for all the three resources is sharply increasing ${ }^{1}$. The inextricable linkages among water, energy and food have been increasing the complexity of all three security issues, requiring a suitably integrated approach to sustainable agriculture, water resources development and energy production worldwide. Thus a nexus approach, called the water-energy-food (WEF) nexus, has been initiated at a global level to integrate management and governance across all three resourcesrelated sectors and scales ${ }^{2}$. This nexus perspective with interdisciplinary solutions could be a good option for adaptation to the changing environment, through enhancing cooperation between and among all sectors.

Since the Bonn 2011 Nexus Conference on 'The Water, Energy and Food Security Nexus-Solutions for the Green Economy' provided the first platform for consideration of the nexus perspective, much of the national and international focus has been on identifying the complex nexus and conducting the policy development and implementation. For instance, in 2013, the Economic and Social Commission for Asia and the Pacific (UNESCAP) issued a report on the Status of the water-food-energy nexus in Asia and the Pacific. The Food and Agriculture

Dan Chen, Peng Zhang, Di Zhang, Bo Bi and Xinchun Cao are in the College of Agricultural Engineering, Hohai University, Nanjing 210098, China; Zhaohui Luo is in the College of Resources and Environmental Sciences, Nanjing Agricultural University, Nanjing 210095, China; Dan Chen and Zhaohui Luo are also in the Department of Agricultural and Biological Engineering, University of Florida, Gainesville 32611, USA.

*For correspondence. (e-mail: 1zhui@njau.edu.cn)
Organization of the United Nations (FAO), Rome, developed an approach of Nexus Rapid Appraisal to assess and manage the WFE nexus to guide the development of 'nexus-sensitive' policies. The International Water Management Institute (IWMI) posted this topic as one of the major issues for finding solutions. The Global Water Partnership (GWP) is focusing on a programme of waterfood-energy-ecosystems nexus. The Stockholm Environment Institute (SEI) offered some major viewpoints and research reports on the water, energy and food nexus. A website called 'The Water, Energy and Food Security Resource Platform' provides independent information funded by the Federal Ministry of Economic Cooperation and Development. In addition, various funding agencies have been supporting scientific research for implementing development plans on the WFE nexus. In 2015, the US National Science Foundation issued a call to fund US $\$ 50$ million for the advancement of research on the nexus ${ }^{3}$. China also incorporated the WFE nexus security into the National Key Research and Development Program of China from 2017. The WFE nexus has become a hot topic of increasing attention for both the scientific and policy communities.

With the widespread attention to the nexus concept, a great number of studies have been conducted on WEF nexus and related fields ${ }^{1,4-9}$. There has been significant progress, including its conceptual framework, interactions among the three cores, nexus quantification or assessment methods and modelling tools, interdisciplinary solutions, governance and implementation. However, no systematic literature reviews have been published from a bibliometric perspective. To fill this research gap, we analysed the performance of WEF nexus-related literature. The overview with document statistics and visualization includes document types and language, 


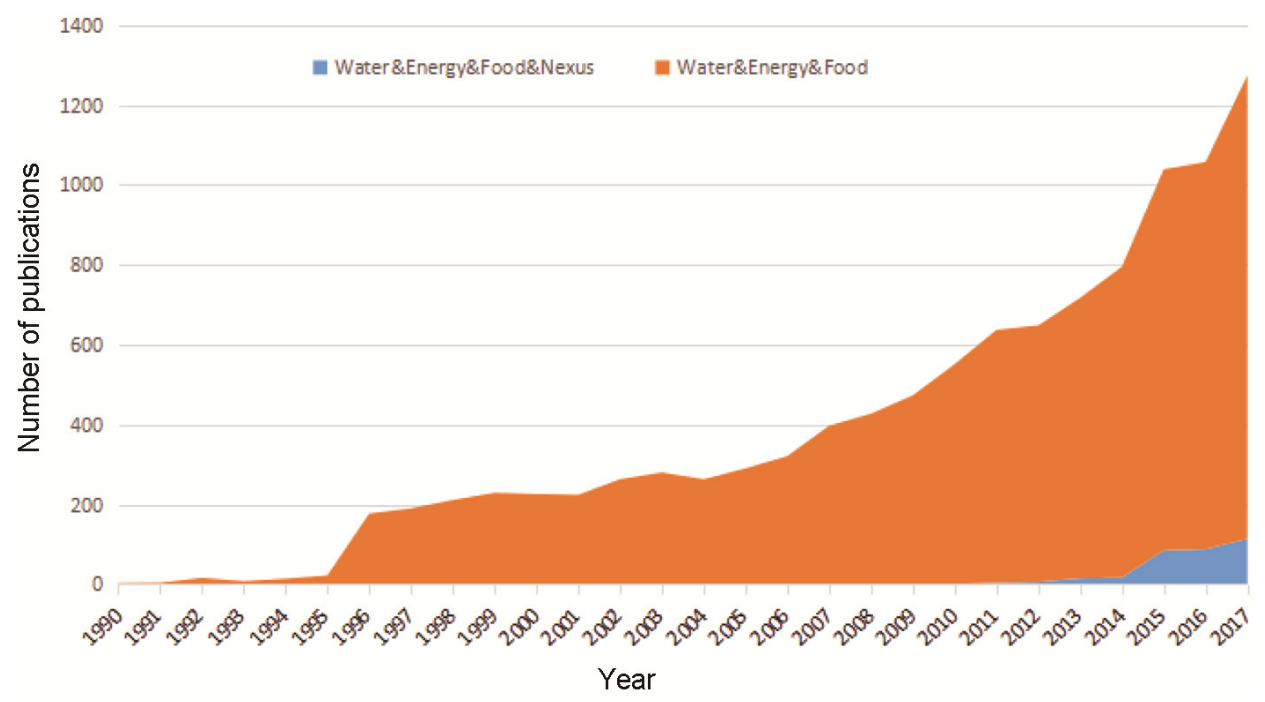

Figure 1. Publication output performance of water-energy-food (WEF) nexus and WEF documents.

changes in publication, distribution of subject categories and journals, contribution of countries and institutions, the most frequently cited publications, keywords, research hotspots and trends, research limitations, challenges and major concerns. The findings in this study will offer an index of cognition in the characteristics and implications of the WEF nexus-related literature as a helpful reference for further studies.

\section{Methods and data sources}

\section{Bibliometric analysis}

The term 'bibliometrics' was first used by Alan Pritchard in 1969 (refs 10-15). Bibliometric analysis is a publication statistical research method ${ }^{16}$. It has been frequently used for systematic evaluation of scientific publications and identification of research phenomena in a specific field $^{10}$. Moreover, CiteSpace software as a tool for progressive knowledge domain visualization was used with bibliometric analysis in this study ${ }^{12}$. CiteSpace can help in the structural and temporal analyses of networks, hybrid node types and cluster views on scientific publications ${ }^{17}$.

\section{Impact factor and h-index}

Two important indicators, viz. impact factor (IF) and $h$-index, are used for bibliometric analysis. IF is one of the common indicators to evaluate the relative influence of journals ${ }^{18}$. It is a standardized indicator calculated using citations and publications of a journal in the last two years ${ }^{19-21}$. The $h$-index is another indicator of individual research achievement from quality and quantity aspects, proposed by Hirsch, in 2005 (ref. 22-24).

\section{Social network analysis}

Social network analysis is used to identify the connections among individuals or groups, and reflect the centrality of individuals and the intensity or strength of ties using statistics $^{25}$. In the network graph, individuals and relationships are represented by weighted nodes and lines respectively, and the nodes playing important roles in network relationships are labelled ${ }^{13,26}$. The contribution of different countries and institutions can be evaluated by estimating research collaborations with the development of network theory and computer processing capacities ${ }^{27}$.

\section{Data sources}

As a well-known database, the Web of Science Core Collection by Thomson Reuters was selected as the data source. 'Water' and 'energy' and 'food' were chosen as keywords under the 'topic' option to search the publications from 1986 to 2017 . A total of 10,425 publications were retrieved on 7 June 2018. Considering the rapid development of the concept of 'nexus', it could be more meaningful to add it as the keyword for secondary retrieval analysis (Figure 1). After screening publications containing keywords but not related to the topic, a total of 330 were retrieved. Since the earliest publication year was 2010, the document data from 2010 to 2017 were selected.

\section{Results}

\section{Document types and language of publications}

Articles (226 publications), proceedings papers (48) and reviews (45) were the major contributions, accounting for 
GENERAL ARTICLES

Table 1. Characteristics by year of publication outputs from 2010 to 2017

\begin{tabular}{lrrrrrrr}
\hline Year & TP & AU & AU/TP & PG & PG/TP & NR & NR/TP \\
\hline 2010 & 1 & 13 & 13 & 29 & 29 & 52 & 52 \\
2011 & 4 & 27 & 6.75 & 63 & 15.75 & 263 & 65.75 \\
2012 & 6 & 20 & 3.33 & 83 & 13.83 & 273 & 45.50 \\
2013 & 15 & 39 & 2.6 & 154 & 10.27 & 668 & 44.53 \\
2014 & 17 & 48 & 2.82 & 150 & 8.82 & 898 & 52.82 \\
2015 & 85 & 289 & 3.4 & 1151 & 13.54 & 4701 & 55.31 \\
2016 & 88 & 373 & 4.24 & 1173 & 13.33 & 5288 & 60.09 \\
2017 & 114 & 416 & 3.65 & 1413 & 12.39 & 7155 & 62.76 \\
Total & 330 & 1225 & & 4216 & & 19298 & \\
Average & & & 3.71 & & 12.78 & & 58.48 \\
\hline
\end{tabular}

TP, Number of publications; AU, Number of authors; PG, Page count; NR, Cited reference count; AU/P, $\mathrm{PG} / \mathrm{P}$ and NR/P, Average number of authors, pages and references per articles respectively.

Table 2. Publications of top 10 subject categories

\begin{tabular}{lcc}
\hline Web of Science subject category & Record & Percentage (\%) \\
\hline Environmental sciences & 117 & 35.241 \\
Water resources & 98 & 29.518 \\
Green sustainable science and technology & 51 & 15.361 \\
Environmental studies & 47 & 14.157 \\
Energy fuels & 46 & 13.855 \\
Engineering - environmental & 37 & 11.145 \\
Engineering - civil & 30 & 9.036 \\
Engineering - chemical & 26 & 7.831 \\
Biotechnology and applied microbiology & 15 & 4.518 \\
Meteorology and atmospheric sciences & 14 & 4.217 \\
\hline
\end{tabular}

$96.67 \%$ of the total published literature. Other types of documents accounted for less than $3.5 \%$, including editorial materials, meeting abstracts, book chapters, book reviews and corrections. The publications were all in English, possibly because databases mainly collect publications in that language.

\section{Characteristics of publications}

Table 1 displays the characteristics of 330 publications. There are a few publications from 2010 to 2012, but after 2012 the annual number increases steadily with a sharp growth in 2015. The average article length fluctuates slightly, with an overall average of 12.78 pages. The number of citations per article increases from 44.53 (2013) to 62.76 (2017), without consideration of the years with less publications (2010-2012). There is a rising number of authors from 13 (2010) to 416 (2017), with the average number of authors of a single article being (3.71). Thus, these characteristics indicate that the WEF nexus has become a hot research area with much attention from experts and scholars.

\section{Distribution of subject categories and journals}

The publications involved 64 subject categories according to classification in the Web of Science database. In the top 10 subject categories (Table 2), environmental sciences was the most productive category $(35.241 \%$ of all publications), followed by water resources $(29.518 \%)$, green sustainable science and technology (15.361\%), environmental studies (14.157\%), and energy fuels $(13.855 \%)$. The papers have been in 160 journals. The top 10 productive journals accounted for $36.1 \%$ of all publications (Table 3). Water was the most productive journal with 19 publications $(5.76 \%)$ and ranked 19 th in the subject category of water resources. Three journals, including Environmental Science and Policy, International Journal of Water Resources Development, and Water International were the second most productive journals $(4.55 \%)$. In general, these journals in the subject categories of water resources, and environmental sciences are the most influential ones.

\section{Contribution of countries/territories}

Except for seven publications lacking any affiliation information, the 323 publications covered 66 countries in total for authors' affiliations. In the top 10 countries (Table 4), USA (134) is ahead of the others in the total number of publications, accounting for $40.361 \%$ of the world total, followed by England (70, 21.084\%), Germany (40, 12.048\%), China (26, 7.831\%) and Australia (24, $7.229 \%$ ). Similarly, USA is in the leading position with regard to $h$-index (18), followed by England (16), Germany (12), Australia (9), Italy (9) and China (8). Thus USA contributed the most to WEF nexus research, followed by England and Germany, while the contributions of other countries were slightly insufficient. Figure 2 shows annual publications of the top 5 most productive countries. Figure 3 shows the cooperative relationships among the top 15 productive countries. The larger the circle in Figure 3, more is the number of publications of a country. Large purple-coloured circles for USA, England and Germany represent their primary contributions to WEF nexus research. Similarly, thicker the line, closer is the cooperative relationship between two countries. It is 
Table 3. Top 10 most productive research journals in water-energy-food (WEF) nexus field

\begin{tabular}{|c|c|c|c|c|c|c|c|}
\hline Journal & $\mathrm{TP}$ & Percentage & IF & $h$-Index & $\begin{array}{l}\text { Total } \\
\text { citations }\end{array}$ & $\begin{array}{l}\text { Cited } \\
\text { times per } \\
\text { publication }\end{array}$ & Subject category (TP/TP of SC) \\
\hline Water & 19 & 5.76 & 2.069 & 7 & 108 & 5.68 & Water resources $(19 / 98)$ \\
\hline Environmental Science \& Policy & 15 & 4.55 & 3.826 & 9 & 247 & 16.47 & Environmental sciences $(15 / 117)$ \\
\hline $\begin{array}{l}\text { International Journal of Water Resources } \\
\text { Development }\end{array}$ & 15 & 4.55 & 1.895 & 5 & 94 & 6.27 & Water resources $(15 / 98)$ \\
\hline $\begin{array}{l}\text { Water Alternatives - An Interdisciplinary } \\
\text { Journal on Water Politics and Development }\end{array}$ & 10 & 3.03 & 2.647 & 8 & 170 & 17 & $\begin{array}{l}\text { Water resources }(10 / 98) \\
\text { Environmental studies }(10 / 47)\end{array}$ \\
\hline Advances in Water Resources & 9 & 2.73 & 3.512 & 1 & 4 & 0.44 & Water resources $(9 / 98)$ \\
\hline Current Opinion in Environmental Sustainability & 9 & 2.73 & 4.186 & 5 & 172 & 19.11 & $\begin{array}{l}\text { Environmental sciences }(9 / 117) \\
\text { Green sustainable science and } \\
\quad \text { technology }(9 / 51)\end{array}$ \\
\hline Environmental Science \& Technology & 9 & 2.73 & 6.653 & 4 & 48 & 5.33 & $\begin{array}{l}\text { Environmental sciences }(15 / 117) \\
\text { Engineering - environmental } \\
(9 / 37)\end{array}$ \\
\hline Sustainability & 9 & 2.73 & 2.177 & 2 & 16 & 1.78 & $\begin{array}{l}\text { Environmental sciences }(9 / 117) \\
\text { Environmental studies }(9 / 47) \\
\text { Green sustainable science and } \\
\text { technology }(9 / 51)\end{array}$ \\
\hline
\end{tabular}

IF, Impact factor; TP, Total publications; SC, Subject category.

Table 4. Performance of top 10 most productive countries/territories

\begin{tabular}{lccc}
\hline $\begin{array}{l}\text { Country/ } \\
\text { Territory }\end{array}$ & $\begin{array}{c}\text { Number of } \\
\text { publications }\end{array}$ & Percentage & $h$-Index \\
\hline USA & 134 & 40.361 & 18 \\
England & 70 & 21.084 & 16 \\
Germany & 40 & 12.048 & 12 \\
China & 26 & 7.831 & 8 \\
Australia & 24 & 7.229 & 9 \\
Italy & 23 & 6.928 & 9 \\
The Netherlands & 13 & 3.916 & 6 \\
Sweden & 12 & 3.614 & 7 \\
India & 11 & 3.313 & 5 \\
Sri Lanka & 11 & 3.313 & 6 \\
\hline
\end{tabular}

easily seen that most of the top productive countries usually tend to cooperate with each other.

\section{Contribution of research institutions}

Table 5 presents the primary performance of the top 10 most productive institutions. It is noteworthy that four of them belong to England, and the rest belong to Sri Lanka, USA, Finland, China, Germany and Italy. Oxford University (England) is the most productive institution. The International Water Management Institute (Sri Lanka) and Aalto University (Finland) have the highest $h$-index (6) among these institutions. Figure 4 shows the cooperation network of the most productive institutions. The dense connections indicate that institutions in these countries have close academic cooperation. The purplecoloured circles indicate that the institutions play a significant role in academic collaboration. In general, universities in England occupy a leading position in WEF nexus research.

\section{Research hotspots and trends}

\section{Most frequently cited papers}

Highly cited papers can reflect the hotspots of academic attention in the field of WEF nexus research. Because recent papers might not have adequate citations for their short publication time, it is reasonable to use cited frequency per year as the evaluation index (Table 6). The most frequently cited paper with the highest annual citation of 24.88 by Bazilian et al. was published in Energy Policy in 2011, entitled 'considering the energy, water and food nexus: towards an integrated modelling approach'. Its main contribution is to develop a model framework exploring the relationship among water, energy and food based on the security perspective of developing countries ${ }^{28}$. The second in the list has (17.63) made quantitative evaluation of regional water-energy relations to help policymaking in planning water and energy infrastructure systems ${ }^{29}$. The third (14.5) emphasizes that the water, energy, land and food sectors need to actively seek 


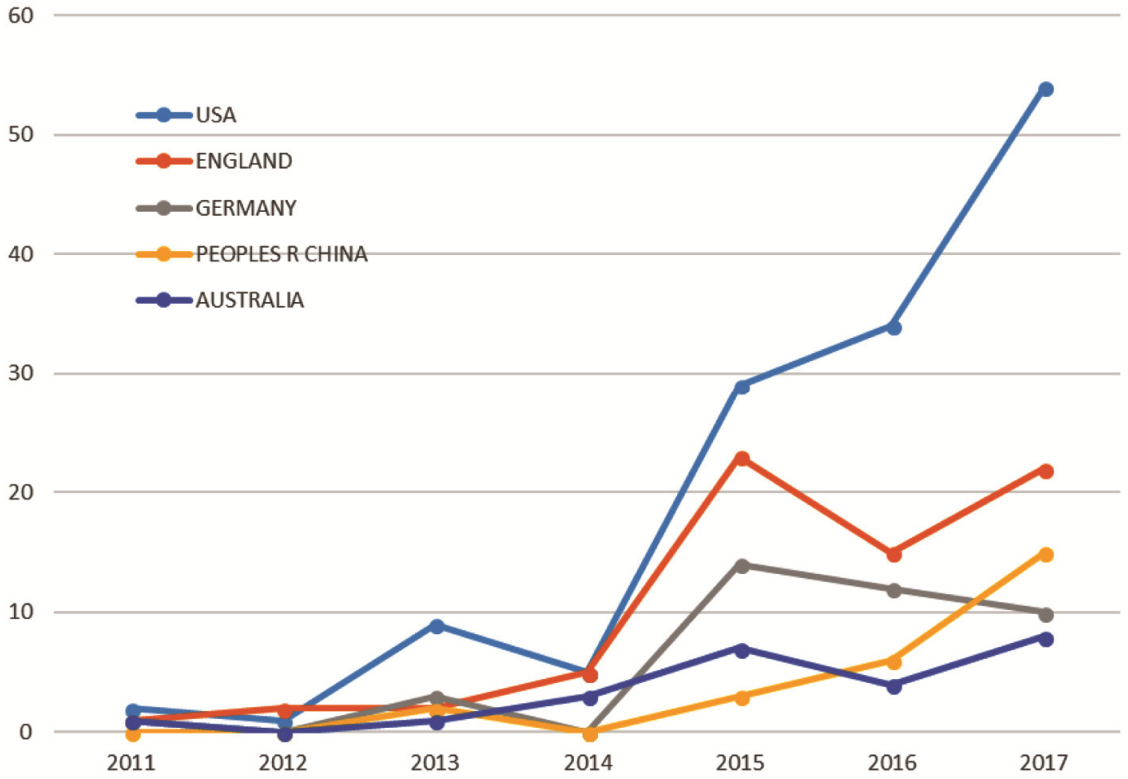

Figure 2. Annual publications of top 5 most productive countries.

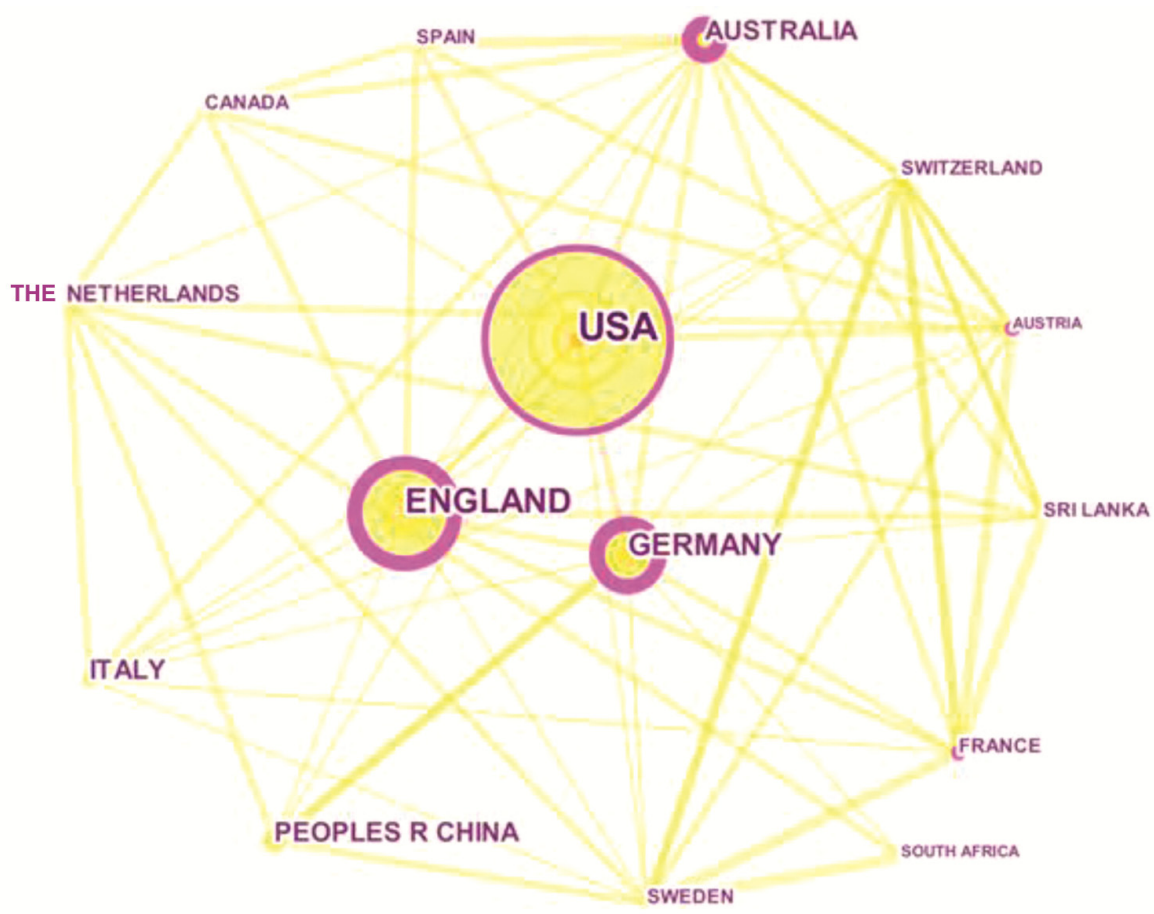

Figure 3. Cooperation network of top 15 most productive countries/territories.

cooperation in overall assessment and investment options to balance the interests of all sectors. It has been recommended that the nexus analysis should be made on human welfare and environment to achieve sustainable development on the premise of the interests of the poor ${ }^{30}$. According to Table 6, the research hotspots include the concept $^{31}$, diverse research perspectives ${ }^{28,32}$, research dimensions and scales $^{31,32}$, and research tools ${ }^{28,29,33}$. Moreover, it is noteworthy that USA and England have four and three highly cited papers in the top 10 respectively.

\section{Keywords analysis and hotspots}

Keywords can reflect the research focus of an article and help readers to recognize the major contents and research directions ${ }^{34}$. Table 7 presents the top 25 frequently used 
Table 5. Performance of top 10 most productive institutions

\begin{tabular}{llcc}
\hline Institution & $\begin{array}{l}\text { Country/ } \\
\text { territory }\end{array}$ & $\begin{array}{c}\text { Number of } \\
\text { publications }\end{array}$ & Percentage \\
\hline University of Oxford & England & 13 & 3.916 \\
International Water Management Institution & Sri Lanka & 9 & 2.711 \\
International Food Policy Research Institution & USA & 8 & 2.41 \\
Aalto University & Finland & 6 & 1.807 \\
Imperial College London & England & 6 & 1.807 \\
University of Exeter & England & 6 & 1.807 \\
University of Surrey & England & 6 & 1.807 \\
Chinese Academy of Sciences & China & 5 & 1.506 \\
Humboldt University of Berlin & Germany & 5 & 3 \\
Polytechnic University of Milan & Italy & 5 & 2 \\
\hline
\end{tabular}

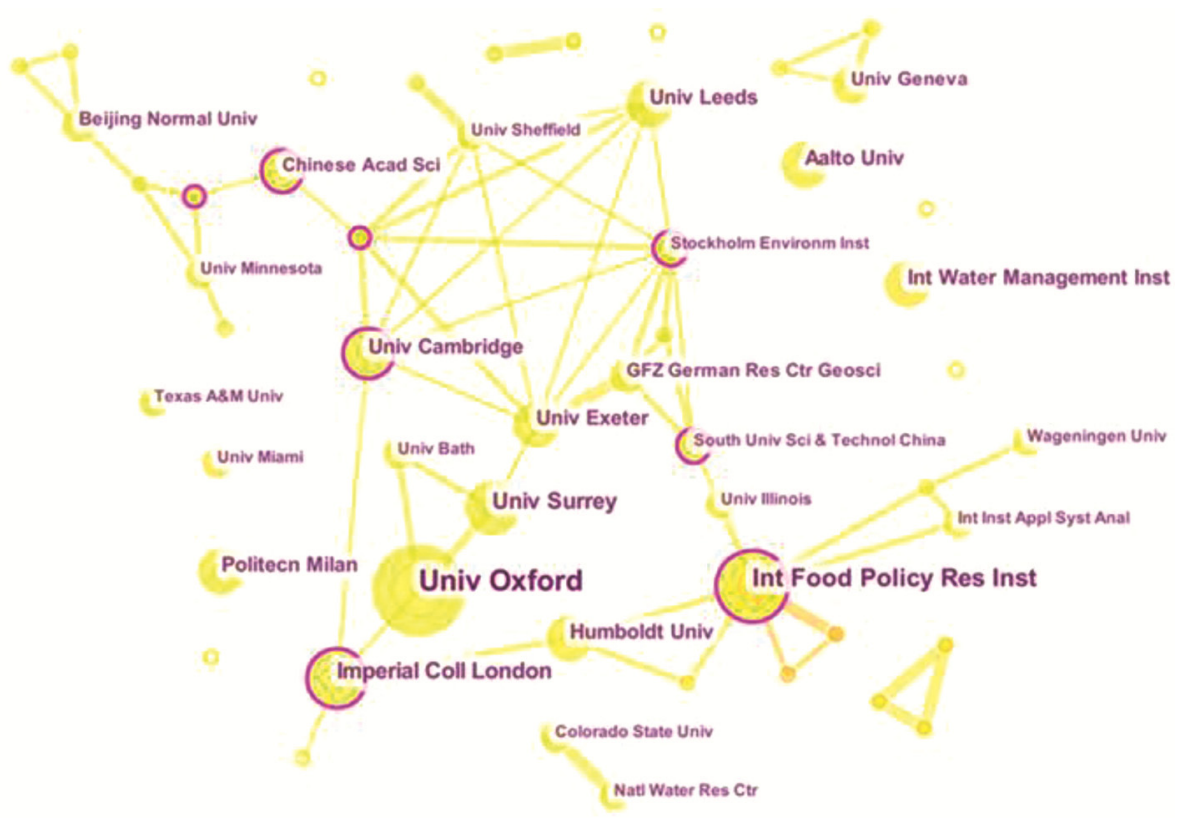

Figure 4. Cooperation network of the most productive institutions.

author keywords and keywords plus. These keywords indicate that research mainly focused on WEF security ${ }^{35,36}$, multiple perspectives ${ }^{32,37}$, research tools ${ }^{38,39}$, and sustainable development strategies ${ }^{32,40}$.

In order to further identify the research patterns in different countries/territories, the keywords in the top 15 productive countries were analysed. Figure 5 shows the top 25 frequently used keywords in publications from not less than nine countries, while the remaining 15 keywords were shared among eight countries or fewer. Moreover, countries in the top three leading positions for keywords include USA (25), England (23) and Germany (17). In addition, most of these countries have their own specific keywords. For USA, 'modeling' and 'network analysis' attracted more attention ${ }^{41,42}$. For England, 'complexity' emphasized that WEF nexus was a complex system ${ }^{43}$, and 'livelihoods' indicated that livelihood perspective frameworks for implementing nexus were key to achieving sustainable development ${ }^{32}$. For Germany, more emphasis was placed on 'trade-off' to address the challenges ${ }^{44}$, and 'hydropower' with great attention to WEF nexus discussions ${ }^{45,46}$

To identify the trend of hotspots, Figure 6 presents a time-zone view of keywords. The keywords were divided into five parts in the order of appearance, to explore the WEF nexus research process. The first part included 'climate change' accounting for the research background. The second included 'food safety', 'management' and 'governance', which show the various challenges and need of comprehensive management of resources. The third including 'nexus', 'water', 'food', 'energy', 'resource' and 'system' indicated that scholars have been focusing on the complex relationship as the nexus among these three core resources. The fourth included 'perspective', 'framework', 'sustainability', 'future', 'challenge', 'life cycle assessment', 'water footprint', and so on. It showed that recognition of the WEF nexus needs a more systematic perspective and deeper conceptual framework 
GENERAL ARTICLES

Table 6. Characteristics of the most frequently cited publications

\begin{tabular}{|c|c|c|c|c|c|}
\hline Year & $\begin{array}{l}\text { Annual } \\
\text { citation }\end{array}$ & Title & Journal & Author & Country/territory \\
\hline 2011 & 24.88 & $\begin{array}{l}\text { Considering the energy, water and food nexus: } \\
\text { Towards an integrated modelling approach }\end{array}$ & Energy Policy & Bazilian, M. et al. & Austria \\
\hline 2011 & 17.63 & $\begin{array}{l}\text { The water-energy nexus in Middle East } \\
\text { and North Africa }\end{array}$ & Energy Policy & $\begin{array}{l}\text { Siddiqi, A. and } \\
\text { Anadon, L. D. }\end{array}$ & USA \\
\hline 2013 & 14.5 & $\begin{array}{l}\text { The nexus across water, energy, land } \\
\text { and food (WELF): potential for improved } \\
\text { resource use efficiency? }\end{array}$ & $\begin{array}{l}\text { Current Opinion in } \\
\text { Environmental } \\
\text { Sustainability }\end{array}$ & Ringler, C. e.al. & USA \\
\hline 2014 & 14.2 & $\begin{array}{l}\text { Food, water, and energy security in South Asia: } \\
\text { a nexus perspective from the Hindu Kush } \\
\text { Himalayan region }\end{array}$ & $\begin{array}{l}\text { Environmental Science } \\
\quad \& \text { Policy }\end{array}$ & Rasul, G. & Nepal \\
\hline 2015 & 11.5 & $\begin{array}{l}\text { Water governance in a comparative perspective: } \\
\text { from IWRM to a 'nexus' approach? }\end{array}$ & $\begin{array}{l}\text { Water alternatives - an } \\
\text { Interdisciplinary } \\
\text { Journal on Water Politics } \\
\text { and Development }\end{array}$ & Benson, D. et al. & England \\
\hline 2015 & 11.25 & $\begin{array}{l}\text { Sustainable development and the water-energy- } \\
\text { food nexus: a perspective on livelihoods }\end{array}$ & $\begin{array}{l}\text { Environmental Science \& } \\
\quad \text { Policy }\end{array}$ & Biggs, E. M. et al. & England \\
\hline 2016 & 9.33 & $\begin{array}{l}\text { The water-energy-food nexus and process } \\
\text { systems engineering: A new focus }\end{array}$ & $\begin{array}{l}\text { Computers \& Chemical } \\
\text { Engineering }\end{array}$ & $\begin{array}{l}\text { Garcia, D. J. and } \\
\text { You, F. Q. }\end{array}$ & USA \\
\hline 2015 & 9 & $\begin{array}{l}\text { Climate and southern Africa's water-energy- } \\
\text { food nexus }\end{array}$ & Nature Climate Change & Conway, D. et al. & England \\
\hline 2015 & 8.75 & $\begin{array}{l}\text { China's water security: current status, } \\
\text { emerging challenges and future prospects }\end{array}$ & $\begin{array}{l}\text { Environmental Science \& } \\
\quad \text { Policy }\end{array}$ & Jiang, Y. & The Netherlands \\
\hline 2014 & 8.4 & $\begin{array}{l}\text { The energy-water-food nexus: Strategic } \\
\text { analysis of technologies for transforming } \\
\text { the urban metabolism }\end{array}$ & $\begin{array}{l}\text { Journal of Environmental } \\
\text { Management }\end{array}$ & Walker, R. V. et al. & USA \\
\hline
\end{tabular}

to meet the challenges. 'Model' was the most dominant keyword in the fifth part, which demonstrated that scholars have focused on modelling the nexus. With rapid development of the big data era and information technology, the trend is to develop comprehensive conceptual frameworks and quantitative analysis models with real-time feedback on the contributions of interdisciplinary subjects and international cooperation.

\section{Discussion}

Analyses of highly cited papers and keywords could offer clues for potential research trends. Yet there are many limitations and challenges for the current studies, possibly resulting from complexity of climate change and human activities, different understandings of the nexus, selection of system boundary, differences at macro or microscales and space-time scales, data availability and uncertainty, methodologies adaptability, and gaps between theory and practice. The main concerns include concept and mechanism, research dimensions and methodologies of the nexus as follows.

(1) Concept and mechanism of the nexus: Since the term 'WEF nexus' was originally coined by the World Economic Forum in 2011, its concept has been consi- dered by different scholars from multiple perspectives. Nexus can be used to indicate the close ties among different subjects ${ }^{47,48}$, and be seen as a method of linking the ideas and actions of stakeholders in different departments and levels to achieve sustainable development. These efforts could help in better understanding of the nexus. However, it has not formed a unified concept in academia due to differences in emphasis and geopolitical background $^{49}$. Its underlying mechanism still needs to be identified in-depth at different space-time scales, to fill the knowledge gaps in interactions among ecological, social and economic dimensions ${ }^{47,48}$. Although various factors have impacts on understanding the nexus, conceptual interpretation is taking shape from a multidisciplinary perspective for building a framework with regional features. The development of nexus thinking would improve holistic and integrated solutions for the balances among water, energy and food.

(2) Research dimensions: The WEF nexus is a governance approach to address resource shortages and ensure the security of water, energy and food, also incorporating ecosystem and resource utilization stakeholders ${ }^{2}$. Based on the concept of livelihood, the nexus framework not only considers the security of sustainable development, but also guarantees the fairness of regional and 


\section{GENERAL ARTICLES}

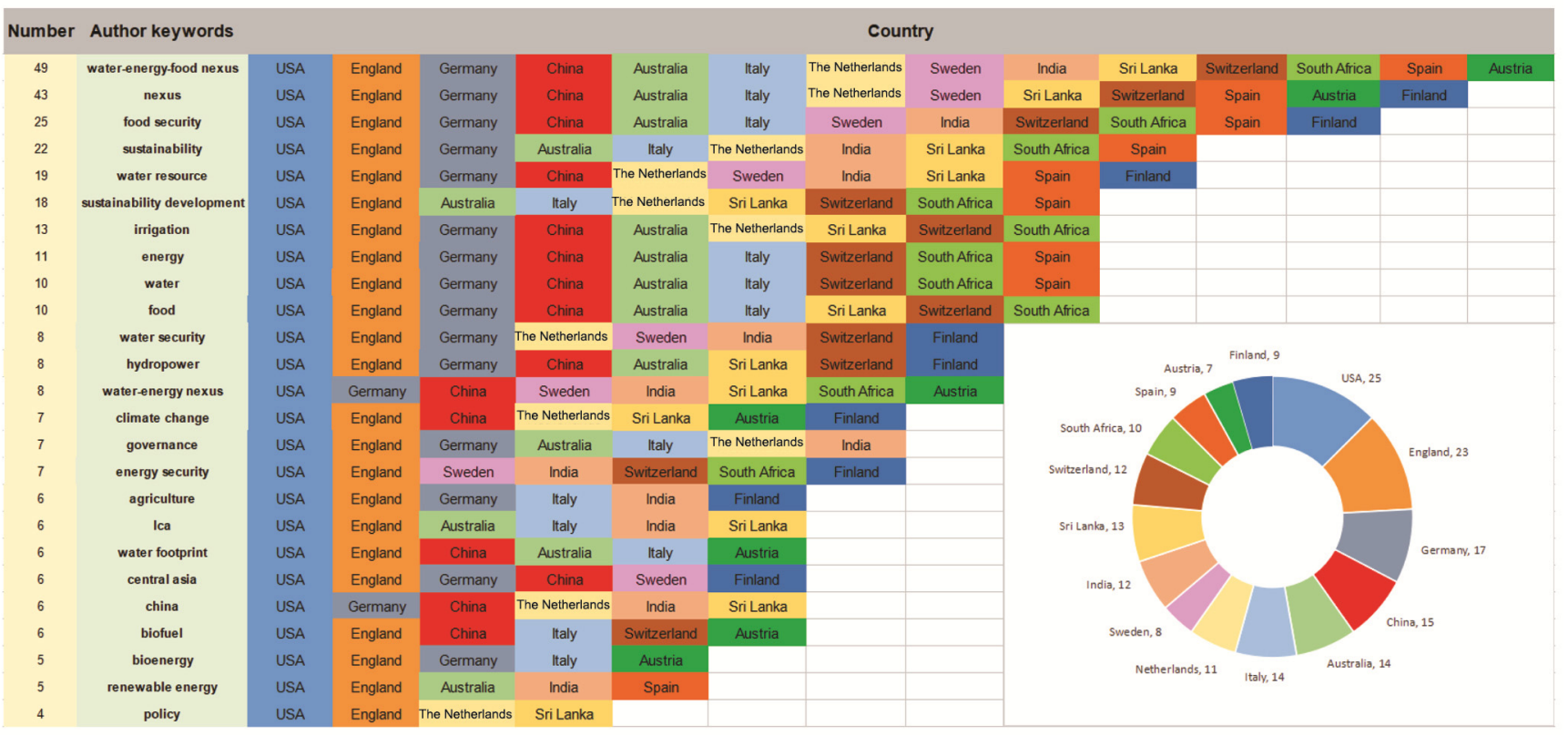

Figure 5. Co-occurrence of author keywords among countries.

Table 7. Top 25 frequently used author keywords and keywords plus used during $2010-17$

\begin{tabular}{|c|c|c|}
\hline Rank & Author keywords & Keywords plus \\
\hline 1 & Sustainability & Climate change \\
\hline 2 & Food security & Management \\
\hline 3 & Agriculture & Security \\
\hline 4 & Bioenergy & Perspective \\
\hline 5 & Climate change & System \\
\hline 6 & Irrigation & Impact \\
\hline 7 & Renewable energy & Resource \\
\hline 8 & Water security & Land \\
\hline 9 & Governance & Consumption \\
\hline 10 & Energy security & River basin \\
\hline 11 & Sustainability development & Governance \\
\hline 12 & Life cycle assessment & Footprint \\
\hline 13 & Water footprint & Policy \\
\hline 14 & Central Asia & United states \\
\hline 15 & China & Agriculture \\
\hline 16 & Water resource & Irrigation \\
\hline 17 & Hydropower & China \\
\hline 18 & Policy & Framework \\
\hline 19 & Biofuel & Sustainability \\
\hline 20 & South Asia & Life cycle assessment \\
\hline 21 & IWRM & Environment \\
\hline 22 & Transboundary river & Challenge \\
\hline 23 & Mekong & Hydropower \\
\hline 24 & Resilience & Water footprint \\
\hline 25 & South east Asia & Bioenergy \\
\hline
\end{tabular}

individual access to resources. Thus, it is necessary to conduct research from diversified perspectives to reflect the interrelationship among water, energy and food in different regions. Moreover, the study could not be limited by the interrelationship of three core resources. Research dimensions can be extended to more relevant resources or drivers, such as water-energy-land-food ${ }^{30}$, water-energyclimate-food $^{50}$, and ecosystem-water-food-energy nexus ${ }^{51}$. Previous studies mainly focused on regional scales, requiring multi-sectoral cooperation across departments due to the increasing difficulties in resources integration. More case studies at local, regional and global levels are needed to enhance understanding of the nexus and its implementation as a management tool. These dimensions also should involve the interrelationship between local and global challenges and economic as well as population growth, by rethinking established ways of resources management. In addition, an appropriate system boundary for nexus analysis at a certain scale should be carefully selected to avoid the uncertainty of results.

(3) Methods, tools and modelling: Since WEF nexus studies involve a wide variety of targeting subjects, system boundaries and scales, data availability and decision-making requirements, various methodologies have been developed or used worldwide in recent years. Several scholars have systematically reviewed the existing methods, tools and modelling approaches. For instance, Endo et al. $^{52}$ classified the methods as qualitative or quantitative for interdisciplinary and transdisciplinary research approaches. Wicaksono et al. ${ }^{53}$ compared several computer models or tools, including Impact Water, WESim, CLEW, Sankey diagram, MuSIASEM, WEF Nexus Tool 2.0, and ANEMI. Kaddoura et al. ${ }^{39}$ reviewed several modelling tools used for integrated policy making. Zhang et al. ${ }^{1}$ mainly discussed eight approaches, including investigation and statistical methods, computable general equilibrium model, econometric analysis, ecological network analysis, life-cycle analysis, system dynamics model, agent-based modelling and integrated 
index. Albrecht et al. ${ }^{54}$ highlighted 18 studies promising advances to guide future research in nexus analytical tools and methods, through deriving their innovation, context, collaboration, and implementation. Despite progress in nexus methodologies, each method has its own advantages, disadvantages and adaptabilities. It might be indeed difficult or impractical to develop a universal method, tool or modelling approach for all situations in theory and practice. To help better manage water, energy and food resources, future researches in nexus methods could need to strengthen the interdisciplinary collaboration, combination with multi-source data and information, integrated software platforms and tools for systematic analysis, integration of various scenarios simulation and multisectoral policies, and involvement of policy makers and stakeholders. Since the complexity mechanism of nexus still needs a deep understanding, the nexus analytical tools and methods could be further improved and developed ${ }^{7,9,28,51,55,56}$.

\section{Conclusion}

Due to the increasing and interrelated pressures on water, energy and food, the nexus perspective has been widely acknowledged as an interdisciplinary solution. To understand the developing process and trends of WEF nexusrelated research, the present study provides a systematic overview of the scientific research using the bibliometric analysis. The number of publications and citations has gradually increased in recent years. Most studies focus on the subject categories of environmental sciences and water resources. Water and Environmental Science \& Policy are the main journals in this field, with the largest number of publications (19) and the highest $h$-index (9) respectively. At the national level, USA (40.36\%) is the most productive country, followed by England (21.08\%) and Germany (12.05\%). Oxford University (England) has

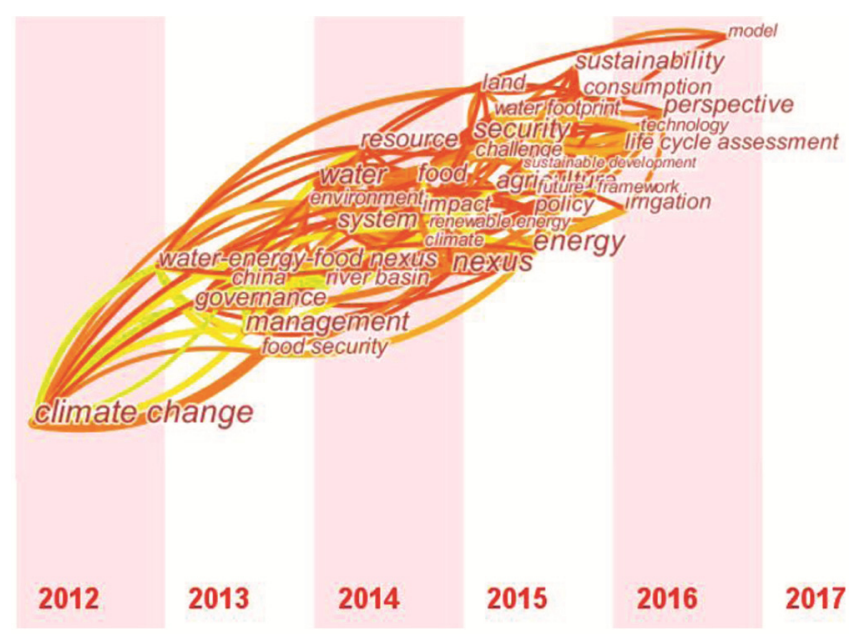

Figure 6. Time-zone view of keywords. the highest number of publications (13), followed by the International Water Management Institute (Sri Lanka; 9) and the International Food Policy Research Institute (USA; 8). Academic cooperation among institutions and countries has become popular. The analyses of frequently cited papers and keywords revealed the research hotspots and trends. After identifying the limitations and challenges for the current studies, three main concerns, including concept and mechanism, research dimensions and methodologies of the nexus have been raised for further studies. This bibliometric analysis provides a holistic picture of WEF nexus-related literature and research directions. These findings will be helpful to provide references for future studies.

1. Zhang, C., Chen, X., Li, Y., Ding, W. and Fu, G., Water-energyfood nexus: concepts, questions and methodologies. $J$ Clean Prod., 2018, 195, 625-639.

2. Hoff, H., Understanding the nexus. Background paper for the bonn 2011 Conference: The Water, Energy and Food Security Nexus, Stockholm, Sweden, 2011.

3. Romerolankao, P., Mcphearson, T. and Davidson, D. J., The foodenergy-water nexus and urban complexity. Nature Climate Change, 2017, 7, 233-235.

4. Liu, J. et al., Challenges in operationalizing the water-energyfood nexus. Hydrol. Sci. J., 2017, 62, 1714-1720.

5. Chang, Y., Li, G., Yao, Y., Zhang, L. and Yu, C., Quantifying the water-energy-food nexus: current status and trends. Energies, $2016,9,65$

6. Märker, C., Venghaus, S. and Hake, J.-F., Integrated governance for the food-energy-water nexus - the scope of action for institutional change. Renew. Sustain. Energ. Rev., 2018, 97, 290-300.

7. Endo, A., Tsurita, I., Burnett, K. and Orencio, P. M., A review of the current state of research on the water, energy, and food nexus. J. Hydrol. Reg. Stud., 2016, 11.

8. Uen, T.-S., Chang, F.-J., Zhou, Y. and Tsai, W.-P., Exploring synergistic benefits of water-food-energy nexus through multiobjective reservoir optimization schemes. Sci. Total Environ., 2018, 633, 341-351.

9. Li, G., Huang, D., Sun, C. and Li, Y., Developing interpretive structural modeling based on factor analysis for the water-energyfood nexus conundrum. Sci. Total Environ., 2018, 651, 309-322.

10. Jacobs, D., Demystification of bibliometrics, scientometrics, informetrics and webometrics. In 11th DIS Annual Conference, University of Zululand, South Africa, 2010.

11. Mao, G., Liu, X., Du, H., Zuo, J. and Wang, L., Way forward for alternative energy research: A bibliometric analysis during 19942013. Renew. Sustain. Energ. Rev., 2015, 48, 276-286.

12. Chen, D., Liu, Z., Luo, Z. H., Webber, M. and Chen, J., Bibliometric and visualized analysis of emergy research. Ecol. Eng., 2016, 90, 285-293.

13. Zhang, Y., Huang, K., Yu, Y. and Yang, B., Mapping of water footprint research: a bibliometric analysis during 2006-2015. J. Clean Prod., 2017, 149, 70-79.

14. Khan, M. A. and Ho, Y.-S., Top-cited articles in environmental sciences: merits and demerits of citation analysis. Sci. Total Environ., 2012, 431, 122-127.

15. Mao, G., Huang, N., Chen, L. and Wang, H., Research on biomass energy and environment from the past to the future: a bibliometric analysis. Sci. Total Environ., 2018, 635, 1081-1090.

16. Liu, X., Liang, Z. and Song, H., Global biodiversity research during 1900-2009: a bibliometric analysis. Biodiver. Conserv., 2011, 20, 807-826. 


\section{GENERAL ARTICLES}

17. Chen, C., CiteSpace II: detecting and visualizing emerging trends and transient patterns in scientific literature. J. Am. Soc. Inf. Sci. Technol., 2006, 57, 359-377.

18. Chiu, W. T. and Ho, Y. S., Bibliometric analysis of tsunami research. Scientometrics, 2007, 73, 3-17.

19. Buela-Casal, G., What do the scientists think about the impact factor? Scientometrics, 2012, 92, 281-292.

20. Garfield, E., The history and meaning of the journal impact factor. $J A M A, 2006,295,90-93$.

21. Fu, H. Z., Ho, Y. S., Sui, Y. M. and Li, Z. S., A bibliometric analysis of solid waste research during the period 1993-2008. Waste Manage., 2010, 30, 2410-2417.

22. Hirsch, J. E., An index to quantify an individual's scientific research output that takes into account the effect of multiple coauthorship. Scientometrics, 2010, 85, 741-754.

23. Hirsch, J. E., An index to quantify an individual's scientific research output. Proc. Natl. Acad. Sci. USA, 2005, 102, 16569-16572.

24. Hirsch, J. E. and Buela-Casal, G., The meaning of the h-index. Int. J. Clin. Health Psychol., 2014, 14, 161-164.

25. Newman, M. E. J. and Newman, M. E. J. Scientific collaboration networks. I. Network construction and fundamental results. Phys. Rev. E, 2001, 64, 016131.

26. Ye, Q., Song, H. and Li, T., Cross-institutional collaboration networks in tourism and hospitality research. Tourism Manage. Perspect., 2012, 2-3, 55-64.

27. Nunkoo, R., Gursoy, D. and Ramkissoon, H., Developments in hospitality marketing and management: social network analysis and research themes. J. Hosp. Market. Manage., 2013, 22, 269-288.

28. Bazilian, M. et al., Considering the energy, water and food nexus: towards an integrated modelling approach. Energy Policy, 2011, 39, 7896-7906.

29. Siddiqi, A. A. and Diaz, L., The water-energy nexus in Middle East and North Africa. Energ. Policy, 2011, 38, 4529-4540.

30. Ringler, C., Bhaduri, A. and Lawford, R., The nexus across water, energy, land and food (WELF): potential for improved resource use efficiency? Curr. Opin. Environ. Sust., 2013, 5, 617-624.

31. Benson, D., Gain, A. K. and Rouillard, J. J., Water governance in a comparative perspective: from IWRM to a 'nexus' approach? Water Altern., 2015, 8, 756-773.

32. Biggs, E. M. et al., Sustainable development and the waterenergy-food nexus: a perspective on livelihoods. Environ. Sci. Policy, 2015, 54, 389-397.

33. Garcia, D. J. and You, F., The water-energy-food nexus and process systems engineering: a new focus. Comput. Chem. Eng., 2016, 91, 49-67.

34. Hou, Q., Mao, G., Zhao, L., Du, H. and Zuo, J., Mapping the scientific research on life cycle assessment: a bibliometric analysis. Int. J. Life Cycle Assess., 2015, 20, 541-555.

35. de Amorim, W. S. et al., The nexus between water, energy, and food in the context of the global risks: an analysis of the interactions between food, water, and energy security. Environ. Impact Assess. Rev., 2018, 72, 1-11.

36. Mirzabaev, A. et al., Bioenergy, food security and poverty reduction: trade-offs and synergies along the water-energy-food security nexus. Water Int., 2015, 40, 772-790.

37. Chen, S. and Chen, B., Urban energy-water nexus: a network perspective. Appl. Energ., 2016, 184, 905-914.

38. Daher, B. T. and Mohtar, R. H., Water-energy-food (WEF) nexus tool 2.0: guiding integrative resource planning and decisionmaking. Water Int., 2015, 40, 748-771.

39. Kaddoura, S. and Khatib, S. E., Review of water-energy-food nexus tools to improve the nexus modelling approach for integrated policy making. Environ. Sci. Policy, 2017, 77, 114-121.

40. Giupponi, C. and Gain, A. K., Integrated spatial assessment of the water, energy and food dimensions of the sustainable development goals. Reg. Environ. Change, 2017, 17, 1881-1893.
41. Zhang, X. and Vesselinov, V. V., Integrated modeling approach for optimal management of water, energy and food security nexus. Adv. Water Resour., 2017, 101, 1-10.

42. Vora, N., Shah, A., Bilec, M. M. and Khanna, V., Food-energywater nexus: quantifying embodied energy and ghg emissions from irrigation through virtual water transfers in food trade. ACS Sust. Chem. Eng., 2017, 5, 2119-2128.

43. Howarth, C. and Monasterolo, I., Opportunities for knowledge co-production across the energy-food-water nexus: making interdisciplinary approaches work for better climate decision making. Environ. Sci. Policy, 2017, 75, 103-110.

44. Kurian, M., The water-energy-food nexus: trade-offs, thresholds and transdisciplinary approaches to sustainable development. Environ. Sci. Policy, 2016, 68, 97-106.

45. Hennig, T., Damming the transnational Ayeyarwady Basin. Hydropower and the water-energy nexus. Renew. Sust. Energy Rev., 2016, 65, 1232-1246.

46. Hennig, T., Wang, W., Magee, D. and He, D., Yunnan's fastpaced large hydropower development: a powershed-based approach to critically assessing generation and consumption paradigms. Water, 2016, 8, 476.

47. Allouche, J., Middleton, C. and Gyawali, D., Technical veil, hidden politics: interrogating the power linkages behind the nexus. Water Altern., 2015, 8, 610-626.

48. Biba, S., The goals and reality of the water-food-energy security nexus: the case of China and its southern neighbours. Third World Q., 2015, 37, 51-70.

49. Gain, A. K., Giupponi, C. and Benson, D., The water-energy-food (WEF) security nexus: the policy perspective of Bangladesh. Water Int., 2015, 40, 895-910.

50. Beck, M. B. and Walker, R. V., On water security, sustainability, and the water-food-energy-climate nexus. Front. Environ. Sci. Eng., 2013, 7, 626-639.

51. Karabulut, A. et al., Mapping water provisioning services to support the ecosystem-water-food-energy nexus in the danube river basin. Ecosyst. Serv., 2016, 17, 278-292.

52. Endo, A. et al., Methods of the water-energy-food nexus. Water, 2015, 7, 5806-5830.

53. Wicaksono, A., Jeong, G. and Kang, D., Water, energy, and food nexus: review of global implementation and simulation model development. Water Policy, 2017, wp2017214.

54. Albrecht, T. R., Crootof, A. and Scott, C. A., The water-energyfood nexus: a systematic review of methods for nexus assessment. Environ. Res. Lett., 2018, 13, 043002.

55. Mccornick, P. G., Awulachew, S. B., Abebe, M. and Priscoli, J. D., Water-food-energy-environment synergies and tradeoffs: major issues and case studies. Water Policy, 2008, 10, 23-36.

56. Guillaume, J. H. A., Kummu, M., Eisner, S. and Varis, O., Transferable principles for managing the nexus \& 58; lessons from historical global water modelling of central Asia. Water, 2015, 7, 4200-4231.

ACKNOWLEDGEMENTS. This research is supported by the National Key Research and Development Program of China (2017YFC040320502), the Fundamental Research Funds for the Central Universities, China (2018B12414), Australian Research Council for Discovery Project Grant (DP170104138), Canberra, Australia and a project funded by the Priority Academic Program Development of Jiangsu Higher Education Institutions (PAPD).

Received 5 November 2018; revised accepted 24 May 2019

doi: $10.18520 / \mathrm{cs} / \mathrm{v} 117 / \mathrm{i} 4 / 577-586$ 